\title{
Cross-sectional analysis of self-reported sedentary behaviors and chronic knee pain among South Korean adults over 50 years of age in KNHANES 2013-2015
}

Sook-Hyun Lee ${ }^{1}$, Chihyoung Son ${ }^{2}$, Sujung Yeo ${ }^{3}$ and In-Hyuk Ha ${ }^{7^{*}}$ (D)

\begin{abstract}
Background: An increasing amount of evidence supports an association between sedentary behaviors and chronic knee pain. However, the association between the total daily duration of sedentary behavior and chronic knee pain in the general population remains unclear. We aimed to analyze the association between sedentary behavior and chronic knee pain in a study population representative of the general Korean population aged > 50 years while also considering the physical activity or body mass index (BMI).

Methods: This cross-sectional study used data from the 6th Korean National Health and Nutrition Examination Survey (KNHANES VI) of 2013-2015, which was completed by 22,948 Korean adult participants aged > 50 years. The participants were divided into two groups based on the status of the chronic knee pain. Data were analyzed using multivariable logistic regression after adjustment for age, sex, and individual factors.

Results: Longer sedentary behavior was correlated with chronic knee pain ( $p$ for trend $=0.02$ ). Sedentary behavior exceeding $10 \mathrm{~h} /$ day was significantly associated with chronic knee pain (adjusted odds ratio, 1.28; $p=0.03$ ).

Participants with high levels of physical activity were less likely to suffer from chronic knee pain (adjusted odds ratio, 0.78; $p=0.00$ ), and women with over 10 daily hours of sedentary behavior with high levels of physical activity were more likely to have chronic knee pain. A significant association was noted between chronic knee pain and obesity $\left(\geq 30.0 \mathrm{~kg} / \mathrm{m}^{2}\right.$ ) individuals (adjusted odds ratio, 3.48; $p=0.04$ ).

Conclusions: Longer duration of sedentary behaviors was correlated with chronic knee pain. Our study suggests the need to encourage reductions in overall sedentary behavior to $<10 \mathrm{~h}$ daily. A high physical activity level is recommended, particularly for women $>50$ years and those with obesity.
\end{abstract}

Keywords: Chronic knee pain, Self-reported sedentary behavior, Physical activity, Body mass index, Korean National Health and nutrition examination survey

\section{Background}

Osteoarthritis (OA) is the most common form of arthritis and the leading cause of disability globally, with pain being the main symptom. Most adults with OA experience associated pain. Particularly, the pain associated with knee OA develops from intermittent weightbearing pain that evolves to chronic pain [1]. According

\footnotetext{
* Correspondence: hanihata@gmail.com

${ }^{1}$ Jaseng Spine and Joint Research Institute, Jaseng Medical Foundation,

Seoul, Republic of Korea

Full list of author information is available at the end of the article
}

to the clinical criteria of the American Rheumatology Society for the diagnosis of knee OA, age 50 years or older is considered a clinical diagnostic criterion [2]. Approximately $25 \%$ of the population aged 50 years or older experiences chronic pain from knee OA [3, 4]. The prevalence of OA was $12.5 \%$ among adults $>50$ years of age. The prevalence was $4.7 \%$ among patients in their $50 \mathrm{~s}, 14.0 \%$ in those in their $60 \mathrm{~s}$, and $26.1 \%$ in those in their 70s [5].

OA imposes a substantial burden on individuals and society. The burden of $\mathrm{OA}$ and chronic knee pain 
includes direct costs (non-pharmacological or pharmacological treatment, surgery, adverse effects of treatment, long-term care), indirect costs (absenteeism, reduced employment, reduced productivity), and intangible costs (pain, activity limitations, decreased quality of life, fatigue, and reduced social participation) [6]. Chronic knee pain and disability owing to degenerative changes in the cartilage of older adults may reduce the quality of life and cause functional impairment, resulting in a loss of independence [7]. Given the general increase in life expectancy and prevalence of obesity, one would expect the prevalence of knee pain to increase concomitantly [8].

The etiology of chronic knee pain is multifactorial and complex, and several factors, including demographic, clinical, and psychological factors collectively contribute to its severity [9]. In the 2010 National Health and $\mathrm{Nu}$ trition Survey in Korea, the likelihood of chronic knee pain was associated with age, sex, low education, depression, obesity, and radiographic knee OA grade [10].

The decline in physical activity owing to the development of personal transportation (car, motorbike, etc.), increased accessibility to the internet, and increase in the prevalence of a sedentary lifestyle is gradually becoming a global problem [11]. The World Health Organization 2010 Physical activity-Health-Related Guidelines and the Physical Activity Guidelines for Americans 2018 also recommend replacing sedentary behavior with mild physical activity to prevent chronic disease and promote health $[12,13]$. As reported in the 2015-2016 US National Health Nutrition Examination Survey, the average daily sitting time exceeds $8 \mathrm{~h}$ per day and inactivity increases with age [14]. It was also reported that $80 \%$ of the waking time is spent sitting [15, $16]$; moreover, the elderly spent $5.3-9.4 \mathrm{~h}$ per waking day engaging in sedentary behaviors [17].

Sedentary behaviors are defined as activities that do not increase energy consumption much higher than those during resting (metabolic equivalents $\leq 1.5$ ). These behaviors typically include activities, such as time spent sitting or lying down during waking hours $[18,19]$. Specifically, in East Asia, including Korea, individuals commonly adopt seating postures on the floor, such as sitting cross-legged and kneeling [20]. The average adult spends about half of their waking time in a sitting position, perhaps because most occupations involve significant sitting time [21]. In addition, patients with chronic knee pain spend most of their waking hours engaged in sedentary behaviors, mostly because of pain and limitation of range of motion [22].

Physical activity is body movement resulting in energy expenditure by skeletal muscle contraction. Physical activity includes exercise and a wide range of sports as well as all body movements that occur during daily activities
[13]. Based on the American Physical Therapy Association guidelines, moderate- to high-intensity exercises are recommended for patients with non-progressive knee pain, while low-intensity exercises are recommended for patients with generalized pain [13, 23]. Some studies reported that physical activity improves physical function and reduces pain and emphasized the importance of physical activity through guidelines.

The American College of Rheumatology Work Group Panel suggested that knee osteoarthritis patients engage in moderate-intensity (50-70\% maximum heart rate) exercise 3 days per week [23]. Korea recommends lowimpact aerobic exercise in its exercise guidelines [24].

According to the World Health Organization's global recommendations on physical activity for health and Korea's physical activity guidelines, adults aged 18-64 years and those over 65 years should complete at least 150 min of moderate-intensity aerobic physical activity per week, at least $75 \mathrm{~min}$ of vigorous-intensity aerobic physical activity per week, or an equivalent combination thereof $[13,25,26]$. Recent studies reported that more than half of Korean adults do meet the recommendation of at least 30 min of moderate activity on 3 or more days a week for at least 3 months [24].

Older people with chronic knee pain may have lower activity levels than the general population [27]. In the KNHANES V (2010-2012) of individuals aged $\geq 50$ years with radiographic knee osteoarthritis, only $18.6 \%$ met the physical activity recommendations, a level that was significantly lower than the $23.3 \%$ reported for the general population [28]. Older people with chronic knee pain face difficulties performing physical activity and exercise owing to the chronic knee problem itself as well as social and individual factors [29]. To date, no study has investigated the relationship between sedentary behaviors and physical activity in the general Korean population.

Obesity can cause various complications and reportedly influences knee pain [30-32]. Previous studies on the relationship between obesity and duration of sedentary behaviors showed that obesity people tend to have a longer sitting time [33]. However, to the best of our knowledge no previous studies have reported the effects of obesity and sedentary behaviors on chronic knee pain.

This study aimed to analyze the association between the duration of sedentary behavior and chronic knee pain in a study population representative of the general Korean population aged over 50 years while also considering physical activity and obesity.

\section{Methods}

\section{Participants}

Data from Korea's 6th National Health and Nutrition Examination Survey (KNHANES VI), 2013-2015 were 
used in this study. A nationwide, multistage, stratified, clustered, and random sampling method was used, which was proportionally distributed by sex, living area, and age of the Korean population.

A total of 22,948 participants completed the KNHANES VI-1 (2013), VI-2 (2014), and VI-3 (2015) examinations and health surveys. The following participants were excluded: 1 ) those under 50 years of age and 2) those that did not respond to the chronic knee pain, sedentary behaviors, physical activity, and body mass index (BMI) surveys. Therefore, this analysis was confined to 8008 participants aged 50-89 years who answered the chronic knee pain examination survey and for whom no data regarding sedentary behaviors, physical activity, and BMI survey were missing (Fig. 1).

\section{Assessment of covariates}

The participants' demographic and socioeconomic characteristics and lifestyle were assessed using health interviews and examinations. Smoking status was categorized as no (non-/ex-smoker) or yes (current smoker) based on the present smoking status. Alcohol consumption was categorized as none, $<1$ drink/month, 2 drinks/ month to 3 drinks/week, or $\geq 4$ drinks/month. Occupations were categorized as unemployed, office work, sales and services, agriculture, forestry and fishery, or machine fitting and simple labor. Household income was categorized into low, mid-low, mid-high, and high quartiles. Educational level was categorized as $\leq 6$ years, $7-9$ years,
10-12 years, and $\geq 13$ years. Sleep duration was assessed using the following question: "How many hours per day do you usually sleep?"

\section{Chronic knee pain}

Patients with chronic knee pain were evaluated using the following questions based on the classification criteria for idiopathic OA of the knee recommended by the American College of Rheumatology [23]: "Have you complained of knee joint pain for more than 30 days during the last 3 months?" Participants who answered "yes" were asked to describe the severity of the pain using a $0-10$-point numerical rating scale [34].

\section{Sedentary behaviors}

Sedentary behaviors were self-reported using the following question: How much time do you spend sitting or lying down during waking hours? The overall duration of sedentary behaviors was categorized as $<5,5-7,8-10$, or $>10 \mathrm{~h} /$ day $[35,36]$.

\section{Physical activity}

The International Physical Activity Questionnaire measures moderate- and vigorous-intensity physical activity and has tested reliability and validity with objective measurement tools [37]. High physical activity was defined as participating in moderate-intensity physical activity for at least $2 \mathrm{~h}$ and $30 \mathrm{~min}$, vigorous-intensity physical activity for more than $1 \mathrm{~h}$ and $15 \mathrm{~min}$, or a

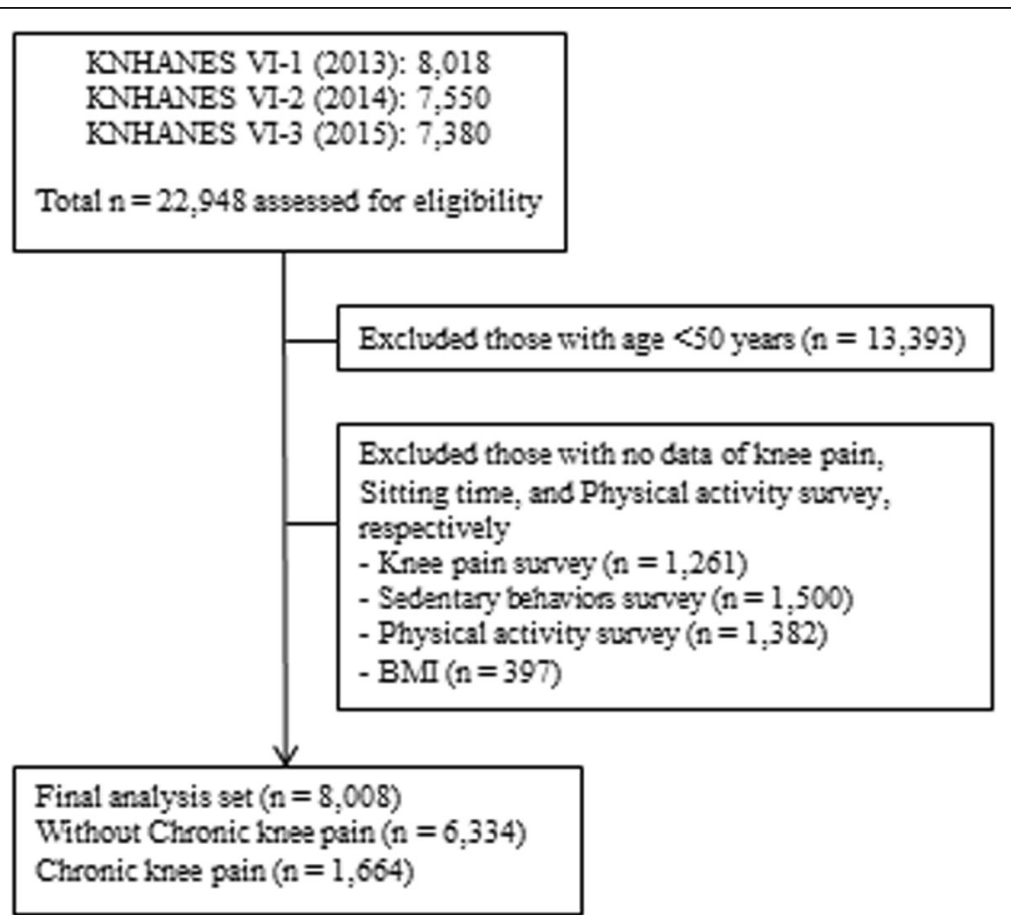

Fig. 1 Flow diagram of the inclusion and exclusion criteria of participants from the 2013-2015 KNHANES VI-1-3 
combination thereof ( $1 \mathrm{~min}$ of high-intensity activity is defined as 2 min of moderate-intensity activity) over a period of 1 week [25, 26]. A lesser level of physical activity was defined as low physical activity.

\section{BMI}

BMI was categorized into underweight $\left(<18.5 \mathrm{~kg} / \mathrm{m}^{2}\right)$, normal weight $\left(18.5-24.9 \mathrm{~kg} / \mathrm{m}^{2}\right)$, overweight $(25.0-29.9$ $\left.\mathrm{kg} / \mathrm{m}^{2}\right)$, and obesity $\left(\geq 30.0 \mathrm{~kg} / \mathrm{m}^{2}\right)[38]$.

\section{Statistical analysis}

All statistical analyses were performed using SAS version 9.4 (SAS Institute Inc., Cary, NC, USA) and consisted of complex sample analysis-stratified cluster sampling with weighted samples.

General characteristics were compared between participants with and without chronic knee pain using Student's t-test and Chi-square test. The latter was used to examine the likelihood associated with chronic knee pain. Furthermore, to identify factors associated with chronic knee pain, odds ratios (ORs) and 95\% confidence intervals (CIs) were calculated through multivariable logistic regression analysis after setting chronic knee pain as the dependent variable and sedentary behaviors as the main independent variable with control for sociodemographic, lifestyle, and health factors. The association between sedentary behavior and chronic knee pain was analyzed using subgroups based on sex, physical activity and BMI. The $p$ values of all analyses performed in this study were two-tailed with a significance level of $<0.05$.

\section{Results}

Participant demographics according to chronic knee pain status

The characteristics of the study population from the survey with and without chronic knee pain are shown in Table 1. A total of 8008 participants were finally analyzed, including 1664 with chronic knee pain and 6344 without. The prevalence of chronic knee pain was $20.8 \%$ among Korean participants older than 50 years. The majority of the participants were women; of whom, 27.4\% had chronic knee pain. In contrast, only $12 \%$ of the men patients had chronic knee pain. The participants with chronic knee pain were older $(65.2 \pm 9.3$ years $)$ than those without $(61.3 \pm 8.7$ years $)(p<0.0001)$. The low PA group $(22.6 \%)$ had a higher prevalence of chronic knee pain than the high PA group $(17.2 \%)(p<0.0001)$. Participants with chronic knee pain demonstrated longer hours of daily sedentary behavior $(6.9 \pm 3.8 \mathrm{~h})$ than those without chronic knee pain $(6.5 \pm 3.6 \mathrm{~h})(p<0.0001)$.

The mean age of the BMI in the group with chronic knee pain $\left(24.7 \pm 3.3 \mathrm{~kg} / \mathrm{m}^{2}\right)$ were older than those in the group without chronic knee pain $\left(24.0 \pm 3.1 \mathrm{~kg} / \mathrm{m}^{2}\right)$ $(p<0.0001)$. In the chronic knee pain group, the prevalence of obesity $\left(30 \mathrm{~kg} / \mathrm{m}^{2}\right)$ was the highest at $32.4 \%$, followed by overweight $\left(25.0-29.9 \mathrm{~kg} / \mathrm{m}^{2}\right)(p<0.0001)$.

Overall, 29.6, 29.9, 24.9, and $15.6 \%$ of the participants with chronic knee pain reported sedentary behaviors for $<5,5-7,8-10$, and $>10 \mathrm{~h} /$ day, respectively. Age, sex, BMI, symptoms of depression, current smoking status, alcohol consumption, occupation, household income, education level, physical activity, and sleep duration were significantly different between participants with and those without chronic knee pain among Korean participants aged $>50$ years. Participants with chronic knee pain were more likely to be older, women, non-smokers, and unemployed with lower income and lower education levels. In terms of lifestyle, participants with chronic knee pain demonstrated lower levels of PA than those without chronic knee pain.

ORs of sedentary behaviors for chronic knee pain by sex Table 2 shows the association between sedentary behaviors and chronic knee pain using multivariable logistic regression by sex. Model 1 was adjusted for age and BMI. Model 2 was adjusted for individual factors (lifestyle factors and health factors), such as smoking, alcohol consumption, occupation, education, household income, physical activity, depression, and sleep duration as well as the factors of Model 1.

Overall, the ORs of chronic knee pain for participants with $>10 \mathrm{~h} /$ day of sedentary behaviors was $1.28(95 \% \mathrm{CI}$, 1.03-1.60) for unadjusted and 1.28 (95\% CI, 1.02-1.61) for Model 2, showing a significant association between chronic knee pain and sedentary behavior of $>10 \mathrm{~h} /$ day $(p=0.03$ and $p=0.03$, respectively). Among women participants, a significant association between chronic knee pain and $>10$ $\mathrm{h} /$ day of sedentary behavior was seen $(p=0.00$ and $p=0.04$, respectively). The ORs of chronic knee pain for $>10 \mathrm{~h} /$ day of sedentary behaviors were 1.56 (95\% CI, 1.22-2.00) for unadjusted model and 1.33 (95\% CI, 1.02-1.74) for Model 2. Regarding the $p$-value for trend, the ORs for chronic knee pain increased with increase in the level of sedentary behavior in unadjusted model $(p=0.00)$ and in Model 2 $(p=0.02)$. Among men, there was no significant association between chronic knee pain and level of sedentary behavior.

\section{ORs of sedentary behaviors for chronic knee pain according to physical activity by sex}

Table 3 shows the association between physical activity and chronic knee pain using multivariable logistic regression by sex. Model 1 was adjusted for age and BMI, while Model 2 was adjusted for individual factors (lifestyle factors and health factors), such as smoking, alcohol consumption, education, household income, depression, and sleep duration as well as the factors of Model 1. 
Table 1 Characteristics of the study population from the survey with and without chronic knee pain

\begin{tabular}{|c|c|c|c|}
\hline Variable & $\begin{array}{l}\text { Without chronic knee pain } \\
\mathrm{n}(\%)\end{array}$ & $\begin{array}{l}\text { Chronic knee pain } \\
\mathrm{n}(\%)\end{array}$ & $P$-value \\
\hline Total & $6344(79.2)$ & $1664(20.8)$ & \\
\hline Age (y) & $61.3 \pm 8.7$ & $65.2 \pm 9.3$ & $<.0001$ \\
\hline \multicolumn{4}{|l|}{ Age, $n(\%)$} \\
\hline $50-59$ & $2583(85.8)$ & $428(14.2)$ & \multirow[t]{4}{*}{$<.0001$} \\
\hline $60-69$ & $2098(79.4)$ & $543(20.6)$ & \\
\hline $70-79$ & $1373(71.8)$ & $539(28.2)$ & \\
\hline$\geq 80$ & $290(65.3)$ & $154(34.7)$ & \\
\hline \multicolumn{4}{|l|}{ Sex, $n(\%)$} \\
\hline Men & $3024(88)$ & $411(12)$ & \multirow[t]{2}{*}{$<.0001$} \\
\hline Women & 3320 (72.6) & $1253(27.4)$ & \\
\hline BMI $\left(\mathrm{kg} / \mathrm{m}^{2}\right)$ & $24.0 \pm 3.1$ & $24.7 \pm 3.3$ & $<.0001$ \\
\hline \multicolumn{4}{|l|}{ BMI (categorical), n (\%) } \\
\hline Underweight (<18.5) & $171(83.0)$ & $35(17.0)$ & \multirow[t]{4}{*}{$<.0001$} \\
\hline Normal (18.5-24.9) & $3984(81.2)$ & $922(18.8)$ & \\
\hline Overweight (25.0-29.9) & 1968 (76.6) & $601(23.4)$ & \\
\hline Obesity $(\geq 30)$ & $221(67.6)$ & $106(32.4)$ & \\
\hline \multicolumn{4}{|l|}{ Smoking status, $n$ (\%) } \\
\hline No & $5308(78.4)$ & $1464(21.6)$ & \multirow[t]{2}{*}{$<.0001$} \\
\hline Yes & $965(85.1)$ & $169(14.9)$ & \\
\hline \multicolumn{4}{|l|}{ Alcohol consumption, $n(\%)$} \\
\hline None & $2333(74.8)$ & $787(25.2)$ & \multirow[t]{4}{*}{$<.0001$} \\
\hline$\leq 1 \mathrm{drink} / \mathrm{mo}$ & $1037(77.9)$ & $295(22.2)$ & \\
\hline 2 drinks/mo to 3 drinks/wk & $1576(83.2)$ & 319 (16.8) & \\
\hline$\geq 4$ drinks/wk & $1334(85)$ & $236(15)$ & \\
\hline \multicolumn{4}{|l|}{ Occupation, n (\%) } \\
\hline Unemployed (student, housewife, etc.) & $2974(74.7)$ & $1006(25.3)$ & \multirow[t]{5}{*}{$<.0001$} \\
\hline Office work & $701(92.1)$ & $60(7.9)$ & \\
\hline Sales and services & $720(85.2)$ & $125(14.8)$ & \\
\hline Agriculture, forestry, and fishery & $505(75.3)$ & $166(24.7)$ & \\
\hline Machine fitting and simple labor & $1430(82.6)$ & $302(17.4)$ & \\
\hline \multicolumn{4}{|l|}{ Household income, $n(\%)^{b}$} \\
\hline Low & $1608(69.1)$ & 719 (30.9) & \multirow[t]{4}{*}{$<.0001$} \\
\hline Mid-low & $1702(79.8)$ & $431(20.2)$ & \\
\hline Mid-high & $1441(83.3)$ & $289(16.7)$ & \\
\hline High & $1566(87.9)$ & $216(12.1)$ & \\
\hline \multicolumn{4}{|l|}{ Education, $n(\%)$} \\
\hline$\leq 6 y$ & $2326(68.8)$ & $1057(31.2)$ & \multirow[t]{4}{*}{$<.0001$} \\
\hline $7-9 y$ & $1127(80.9)$ & $266(19.1)$ & \\
\hline $10-12$ y & $1792(87.5)$ & $256(12.5)$ & \\
\hline$\geq 13$ y & $1086(93.2)$ & $79(6.8)$ & \\
\hline Duration of sleep $(h)$, mean $\pm s d$ & $6.6 \pm 1.4$ & $6.4 \pm 1.7$ & $<.0001$ \\
\hline Depressive symptom, $n(\%)^{c}$ & $307(64.6)$ & $168(35.4)$ & $<.0001$ \\
\hline
\end{tabular}

Physical activity, $\mathrm{n}(\%)$ 
Table 1 Characteristics of the study population from the survey with and without chronic knee pain (Continued)

\begin{tabular}{|c|c|c|c|}
\hline Variable & $\begin{array}{l}\text { Without chronic knee pain } \\
\mathrm{n}(\%)\end{array}$ & $\begin{array}{l}\text { Chronic knee pain } \\
\text { n (\%) }\end{array}$ & $P$-value \\
\hline Low & $4083(77.4)$ & $1195(22.6)$ & $<.0001$ \\
\hline High & $2261(82.8)$ & $469(17.2)$ & \\
\hline Sedentary behaviors $(h)$, mean $\pm s d$ & $6.5 \pm 3.6$ & $6.9 \pm 3.8$ & 0.0145 \\
\hline \multicolumn{4}{|l|}{ Sedentary behaviors (h) ${ }^{d}$} \\
\hline$<5$ & $2123(33.5)$ & $492(29.6)$ & 0.0909 \\
\hline $5-7$ & $1950(30.7)$ & $498(29.9)$ & \\
\hline $8-10$ & $1474(23.2)$ & $415(24.9)$ & \\
\hline$>10$ & 797 (12.6) & $259(15.6)$ & \\
\hline
\end{tabular}

$B M I$ body mass index

Numeric parameters are expressed as means with standard deviation in parentheses, unless stated otherwise. Categorical parameters are expressed as counts with percentages in parentheses

${ }^{a}$ BMI was categorized into underweight $\left(<18.5 \mathrm{~kg} / \mathrm{m}^{2}\right)$, normal $\left(18.5-24.9 \mathrm{~kg} / \mathrm{m}^{2}\right)$, overweight $\left(25.0-29.9 \mathrm{~kg} / \mathrm{m}^{2}\right)$, and obesity $\left(\geq 30.0 \mathrm{~kg} / \mathrm{m}^{2}\right)$

${ }^{b}$ Household income levels were calculated by dividing the total household monthly income with the obtained levels then grouped into quartiles

c Depressive symptoms were defined as individuals who felt sad or experienced other depressive symptoms for 2 consecutive weeks during the past year

${ }^{d}$ Levels of sedentary behaviors were categorized using quartiles: $<5,5-7,8-10$, and $>10 \mathrm{~h} /$ day

Overall, the ORs of chronic knee pain for high physical activity were 0.64 (95\% CI, $0.55-0.73)$ for unadjusted model and 0.78 (95\% CI, 0.67-0.91) for Model 1. In the total population, a significant association was noted between chronic knee pain and high physical activity $(p=0.00$ and $p=0.00$, respectively). A significant association was noted between chronic knee pain and high physical activity ( $p=0.01$ and $p=0.01$, respectively) among men participants. The ORs of chronic knee pain for high physical activity were 0.68 (95\% CI, 0.52-0.89) for unadjusted model and 0.70 (95\% CI, 0.54-0.92) for Model 1 . Women participants showed a significant association between chronic knee pain and physical activity $(p=0.00$ and $p=0.04$, respectively). The ORs of chronic knee pain

Table 2 Association between sedentary behaviors and chronic knee pain using multivariable logistic regression by sex

\begin{tabular}{|c|c|c|c|c|c|c|}
\hline \multirow{2}{*}{$\begin{array}{l}\text { Sedentary } \\
\text { behaviors } \\
4 \text { categories }{ }^{\text {a }} \\
\end{array}$} & \multicolumn{2}{|l|}{ Unadjusted } & \multicolumn{2}{|l|}{ Model 1} & \multicolumn{2}{|l|}{ Model 2} \\
\hline & OR $(95 \% \mathrm{Cl})$ & $P$-value & OR (95\% Cl) & $P$-value & OR (95\% Cl) & $P$-value \\
\hline \multicolumn{7}{|l|}{ Total } \\
\hline$<5$ & 1 & & 1 & & 1 & \\
\hline $5-7$ & $1.02(0.86-1.20)$ & 0.78 & $0.99(0.84-1.159)$ & 0.87 & $1.03(0.87-1.22)$ & 0.73 \\
\hline $8-10$ & $1.11(0.93-1.33)$ & 0.24 & $1.05(0.87-1.26)$ & 0.64 & $1.17(0.96-1.42)$ & 0.12 \\
\hline$>10$ & $1.28(1.03-1.60)$ & 0.03 & $1.21(0.97-1.51)$ & 0.1 & $1.28(1.02-1.61)$ & 0.03 \\
\hline$p$ for trend & $1.08(1.01-1.15)$ & 0.02 & $1.05(0.99-1.13)$ & 0.12 & $1.09(1.02-1.16)$ & 0.02 \\
\hline \multicolumn{7}{|l|}{ Men } \\
\hline$<5$ & 1 & & 1 & & 1 & \\
\hline $5-7$ & $0.83(0.62-1.12)$ & 0.22 & $0.81(0.60-1.08)$ & 0.15 & $0.89(0.63-1.25)$ & 0.50 \\
\hline $8-10$ & $0.93(0.67-1.29)$ & 0.66 & $0.92(0.66-1.28)$ & 0.61 & $1.11(0.78-1.58)$ & 0.57 \\
\hline$>10$ & $1.02(0.67-1.56)$ & 0.93 & $0.99(0.64-1.52)$ & 0.96 & $1.17(0.78-1.75$ & 0.46 \\
\hline $\mathrm{p}$ for trend & $1.00(0.88-1.14)$ & 0.98 & $0.99(0.87-1.13)$ & 0.92 & $1.06(0.94-1.20)$ & 0.36 \\
\hline \multicolumn{7}{|l|}{ Women } \\
\hline$<5$ & 1 & & 1 & & 1 & \\
\hline $5-7$ & $1.11(0.91-1.35)$ & 0.31 & $1.06(0.86-1.30)$ & 0.60 & $1.12(0.91-1.38)$ & 0.30 \\
\hline $8-10$ & $1.21(0.98-1.50)$ & 0.08 & $1.08(0.87-1.35)$ & 0.48 & $1.21(0.96-1.52)$ & 0.10 \\
\hline$>10$ & $1.56(1.22-2.00)$ & 0.00 & $1.27(0.99-1.63)$ & 0.07 & $1.33(1.02-1.74)$ & 0.04 \\
\hline$p$ for trend & $1.14(1.06-1.23)$ & 0.00 & $1.07(0.99-1.15)$ & 0.10 & $1.10(1.01-1.19)$ & 0.02 \\
\hline
\end{tabular}

Multivariable Logistic regression analysis with complex sampling design was performed by adjusting for covariates. OR, odds ratio; $95 \% \mathrm{Cl}, 95 \%$ confidence interval

${ }^{a}$ Levels of sedentary behaviors were categorized using quartiles: $<5,5-7,8-10$, and $>10 \mathrm{~h} /$ day

Model 1 was adjusted for age and BMI

Model 2 was adjusted for Model $1+$ smoking, alcohol consumption, occupation, education, household income, physical activity, depression, and duration of sleep 
Table 3 Association between physical activity and chronic knee pain using multivariable logistic regression by sex

\begin{tabular}{|c|c|c|c|c|c|c|}
\hline \multirow{2}{*}{$\begin{array}{l}\text { Physical activity } \\
2 \text { categories }^{\mathrm{a}}\end{array}$} & \multicolumn{2}{|l|}{ Unadjusted } & \multicolumn{2}{|l|}{ Model 1} & \multicolumn{2}{|l|}{ Model 2} \\
\hline & OR $(95 \% \mathrm{Cl})$ & $P$-value & OR (95\% Cl) & $P$-value & OR $(95 \% \mathrm{Cl})$ & $P$-value \\
\hline \multicolumn{7}{|l|}{ Total } \\
\hline Low physical activity & 1 & & 1 & & 1 & \\
\hline High physical activity & $0.64(0.55-0.73)$ & 0.00 & $0.78(0.67-0.91)$ & 0.00 & $0.86(0.74-1.01)$ & 0.06 \\
\hline \multicolumn{7}{|l|}{ Men } \\
\hline Low physical activity & 1 & & 1 & & 1 & \\
\hline High physical activity & $0.68(0.52-0.89)$ & 0.01 & $0.70(0.54-0.92)$ & 0.01 & $0.79(0.60-1.04)$ & 0.10 \\
\hline \multicolumn{7}{|l|}{ Women } \\
\hline Low physical activity & 1 & & 1 & & 1 & \\
\hline High physical activity & $0.69(0.59-0.82)$ & 0.00 & $0.84(0.70-1.00)$ & 0.04 & $0.90(0.75-1.08)$ & 0.27 \\
\hline
\end{tabular}

for high physical activity were 0.69 (95\% CI, 0.59-0.82) for unadjusted model and 0.84 (95\% CI, 0.70-1.00) for Model 1. However, the associations for total, men, and women participants in the full adjusted model 2 were not significant.

\section{ORs of sedentary behaviors for chronic knee pain by BMI}

Table 4 shows the association between BMI and chronic knee pain using multivariable logistic regression by sex. Model 1 was adjusted for age and model 2 was adjusted for individual factors (lifestyle factors and health factors), such as smoking, alcohol consumption, education, household income, physical activity, depression, and sleep duration as well as factors of Model 1.

Overall, the ORs of chronic knee pain and overweight $\left(25.0-29.9 \mathrm{~kg} / \mathrm{m}^{2}\right)$ were 1.79 (95\% CI, 1.13-2.84) and 1.86 (95\% CI, 1.14-3.04) for Model 1 and Model 2, respectively. A significant association between chronic knee pain and overweight $\left(25.0-29.9 \mathrm{~kg} / \mathrm{m}^{2}\right) \quad(p=0.01$ and $p=0.01$, respectively) was noted. The ORs of chronic knee pain and obesity $\left(\geq 30.0 \mathrm{~kg} / \mathrm{m}^{2}\right)$ were 2.44 (95\% CI, 1.48-4.01) for unadjusted model, 2.64 (95\% CI, 1.59-4.38) for model 1, and 2.45 (1.43-4.21) for Model 2. A significant association was noted between chronic knee pain and obesity $\left(\geq 30.0 \mathrm{~kg} / \mathrm{m}^{2}\right)(p=0.00, p=0.00$, and $p=0.00$, respectively). In $\mathrm{p}$ for trend, the chronic knee pain correlated with BMI in unadjusted model (OR, 1.32; 95\% CI, 1.20-1.46; $p=0.00$ ), Model 1 (OR, 1.34; $95 \% \mathrm{CI}, 1.21-1.48 ; p=0.00$ ) and in Model 2 (OR, 1.34; 95\% CI, 1.14-1.40; $p=0.00$ ).

Among men participants, a significant association was noted between chronic knee pain and obesity $(\geq 30.0 \mathrm{~kg} /$ $\left.\mathrm{m}^{2}\right)(p=0.04)$. The ORs of chronic knee pain for obesity $\left(\geq 30.0 \mathrm{~kg} / \mathrm{m}^{2}\right)$ were 3.17 (95\% CI, 1.06-9.42) for Model 1 and 3.48 (95\% CI, 1.03-11.74) for Model 2. Among the women participants, a significant association was noted between chronic knee pain and obesity $\left(\geq 30.0 \mathrm{~kg} / \mathrm{m}^{2}\right)$. The ORs of chronic knee pain for obesity were 1.97 (95\% CI, 1.12-3.45) for unadjusted model, 2.36 (95\% CI, 1.35-4.14) for Model 1, and 2.01 (95\% CI, 1.12-3.62) for Model 2. Further, the women participants showed a significant association between chronic knee pain and BMI $(p=0.02,0.00$, and 0.02$)$. In $\mathrm{p}$ for trend, chronic knee pain was correlated to BMI in unadjusted model (OR, 1.45; 95\% CI, 1.29-1.63; $p=0.00$ ), Model 1 (OR, 1.45; 95\% CI, 1.28-1.63; $p=0.00)$ and Model 2 (OR, 1.33; 95\% CI, $1.18-1.51 ; p=0.00)$.

\section{ORs of sedentary behaviors and chronic knee pain by high physical activity using multivariable logistic regression by sex}

Additional file 1: Table S1 shows the association between chronic knee pain and sedentary behaviors based on the high levels of physical activity multivariable logistic regression by sex. Model 1 was adjusted for age and individual factors (lifestyle factors and health factors), such as BMI, smoking, alcohol consumption, occupation, education, household income, depression, and duration of sleep.

In the subgroup analysis, the association between chronic knee pain and sedentary behaviors based on high physical activity and sex was analyzed in more detail using multivariable logistic regression (Additional file 1: Table S1). Women participants showed a significant association between chronic knee pain and high physical activity $(p=0.04)$. The OR of chronic knee pain for high levels of physical activity was 1.33 (95\% CI, 1.02-1.74) in Model 3. In $\mathrm{p}$ for trend, chronic knee 
Table 4 Association between BMl and chronic knee pain using multivariable logistic regression by sex

\begin{tabular}{|c|c|c|c|c|c|c|}
\hline \multirow{2}{*}{$\begin{array}{l}\text { BMI } \\
4 \text { categories }^{\mathrm{a}}\end{array}$} & \multicolumn{2}{|l|}{ Unadjusted } & \multicolumn{2}{|l|}{ Model 1} & \multicolumn{2}{|l|}{ Model 2} \\
\hline & OR (95\% Cl) & $P$-value & OR $(95 \% \mathrm{Cl})$ & $P$-value & OR (95\% Cl) & $P$-value \\
\hline \multicolumn{7}{|l|}{ Total } \\
\hline Underweight & 1 & & 1 & & 1 & \\
\hline Normal & $1.18(0.77-1.83)$ & 0.45 & $1.38(0.89-2.16)$ & 0.15 & $1.53(0.95-2.46)$ & 0.08 \\
\hline Overweight & $1.48(0.95-2.32)$ & 0.09 & $1.79(1.13-2.84)$ & 0.01 & $1.86(1.14-3.04)$ & 0.01 \\
\hline Obesity & $2.44(1.48-4.01)$ & 0.00 & $2.64(1.59-4.38)$ & 0.00 & $2.45(1.43-4.21)$ & 0.00 \\
\hline$P$ for trend & $1.32(1.20-1.46)$ & 0.00 & $1.34(1.21-1.48)$ & 0.00 & $1.26(1.14-1.40)$ & 0.00 \\
\hline \multicolumn{7}{|l|}{ Men } \\
\hline Underweight & 1 & & 1 & & 1 & \\
\hline Normal & $1.83(0.74-4.54)$ & 0.19 & $0.70(0.54-0.92)$ & 0.01 & $0.79(0.60-1.04)$ & 0.10 \\
\hline Overweight & $1.58(0.63-3.96)$ & 0.33 & $1.96(0.77-4.94)$ & 0.16 & $2.32(0.83-6.51)$ & 0.11 \\
\hline Obesity & $2.44(0.82-7.28)$ & 0.11 & $3.17(1.06-9.42)$ & 0.04 & $3.48(1.03-11.74)$ & 0.04 \\
\hline $\mathrm{P}$ for trend & $1.00(0.81-1.23)$ & 0.99 & $1.07(0.87-1.31)$ & 0.54 & $1.07(0.87-1.32)$ & 0.50 \\
\hline \multicolumn{7}{|l|}{ Women } \\
\hline Underweight & 1 & & 1 & & 1 & \\
\hline Normal & $0.97(0.61-1.54)$ & 0.90 & $1.13(0.71-1.81)$ & 0.61 & $1.17(0.71-1.93)$ & 0.53 \\
\hline Overweight & $1.53(0.94-2.48)$ & 0.09 & $1.71(1.04-2.79)$ & 0.03 & $1.62(0.97-2.71)$ & 0.07 \\
\hline Obesity & $1.97(1.12-3.45)$ & 0.02 & $2.36(1.35-4.14)$ & 0.00 & $2.01(1.12-3.62)$ & 0.02 \\
\hline $\mathrm{P}$ for trend & $1.45(1.29-1.63)$ & 0.00 & $1.45(1.28-1.63)$ & 0.00 & $1.33(1.18-1.51)$ & 0.00 \\
\hline
\end{tabular}

Multivariable Logistic regression analysis with complex sampling design was performed by adjusting for covariates. OR, odds ratio; $95 \% \mathrm{Cl}, 95 \%$ confidence interval

${ }^{a}$ BMI was categorized into underweight $\left(<18.5 \mathrm{~kg} / \mathrm{m}^{2}\right)$, normal weight $\left(18.5-24.9 \mathrm{~kg} / \mathrm{m}^{2}\right)$, overweight $\left(25.0-29.9 \mathrm{~kg} / \mathrm{m}^{2}\right)$, and obesity $\left(\geq 30.0 \mathrm{~kg} / \mathrm{m}^{2}\right)$ Model 1 was adjusted for age

Model 2 was adjusted for Model $1+$ smoking, alcohol consumption, occupation, education, household income, physical activity, depression, and duration of sleep

pain correlated with sedentary behaviors at high physical activity in unadjusted model (OR, 1.15; 95\% CI, $1.00-1.32 ; p=0.04$ ) and Model 1 (OR, 1.19; 95\% CI, $1.02-1.39 ; p=0.03)$.

\section{ORs ratios of sedentary behaviors and chronic knee pain using multivariable logistic regression by sex}

Additional file 2: Table S2 shows the association between chronic knee pain and sedentary behaviors according to BMI using multivariable logistic regression by sex. Model 1 was adjusted for age and individual factors (lifestyle factors and health factors), such as smoking, alcohol consumption, occupation, education, household income, physical activity, depression, and duration of sleep.

In subgroup analysis, the association between chronic knee pain and sedentary behaviors by BMI and sex was analyzed in further detail using multivariable logistic regression (Additional file 2: Table S2). Women participants showed significant association between chronic knee pain and BMI $(p=0.04)$. The ORs of chronic knee pain for high physical activity was 1.37 (95\% CI, 1.021.84) in Model 1. Meanwhile, women showed no statistically significant differences between sedentary behavior and chronic pain when overweight or obesity. Men participants also showed no statistically significant differences between sedentary behavior and chronic pain with normal weight or overweight. In obesity men participants, statistical analysis could not be performed owing to lack of numbers.

\section{Discussion}

In this study, we analyzed the relationship between sedentary behavior and chronic knee pain among 8008 participants using reliable data that were representative of the general Korean population. Longer sedentary behavior and BMI were correlated with chronic knee pain.

In addition, even with high levels of physical activity, longer sedentary behavior (over than $10 \mathrm{~h}$ /day) was associated with chronic knee pain among women.

A previous study that analyzed data from the KNHANES in 2010-2012 reported that age, women sex, lower education level, obesity, and depression were risk factors for knee pain in adults > 50 years of age [39]. This is consistent with our findings. In our study, participants with chronic knee pain were older, women, non-smokers, and unemployed with lower income and education levels. Further, participants with chronic knee pain had lower levels of physical activity than those without chronic knee pain. 
Knee joints can become stiff while getting out of bed in the morning or after long periods of sitting [40]. OA pain in the knee can lead to knee instability (buckling) owing to secondary patellar imbalance caused by weakening of the quadriceps muscle [41, 42]. In addition, the decrease in quadriceps muscle strength can cause difficulty in movements, such as standing from the sitting position. Continuation of this condition may cause flexion deformation in the knee joint [43]. Knee stiffness limits extension movements, causes an increase in the stress applied to the joints, induces secondary pain, reduces muscle flexibility, and aggravates knee OA by creating a pain loop [44]. Thus, the individual may experience difficulty while performing everyday life activities, such as climbing stairs and self-care.

An earlier clinical study examined the correlation between longer sedentary behaviors and arthritis among obesity men participants and found that longer periods of sedentary behaviors gradually resulted in weakness of the quadriceps muscle, resulting in wear and tear in the area below the patella, causing pain [40]. In one study, obesity and chronic pain were frequently associated with each other, negatively affected each other, and were mediated by a variety of factors (i.e. lifestyle factors, including inflammatory intermediates, mood disorders, sleep deprivation, and biomechanical structural changes). The findings of our study also showed that individual factors (lifestyle and health factors) such as smoking, alcohol consumption, education, household income, physical activity, depression, and sleep duration affected knee pain. Furthermore, our study confirmed the relationship between obesity and knee pain and examined the relationship between sedentary behavior and obesity in subjects with knee pain. Consistent with these findings, our study suggested that obesity individuals were more likely to suffer from chronic knee pain. However, women with normal weight were 1.37 times more likely to suffer from chronic knee pain with $8-10 \mathrm{~h}$ of sedentary behavior than those with $<5 \mathrm{~h}$ of sedentary behaviors.

Promotion of health among the elderly by emphasizing on moderate-intensity aerobic and muscle strengthening activities and by reducing sedentary behaviors is encouraged based on the recommendations of the American College of Sports Medicine and American Heart Association [25]. This is consistent with our results that emphasize the need to reduce sedentary behaviors among adults $>50$ years of age. In addition, according to previous reports on exercise and physical activity behaviors, $44 \%$ of individuals with knee pain reported low levels of physical activity. Our study showed that individuals in the high physical activity group showed lesser tendency for knee pain [27]. In other words, there was a high incidence of chronic knee pain in the low physical activity group, a finding consistent with that in previous studies.

This study had a number of advantages. First, it was based on the reliable data obtained from the Korean government agencies from questionnaires completed by a sample representative of the general Korean population. Second, this was the first study to investigate the relationship between sedentary behaviors and chronic knee pain based on levels of physical activity or BMI. Third, individuals in East Asia, including Korea, commonly sit on the floor in a crossed-leg or kneeling posture; therefore, research investigating the effect of sedentary behaviors on knee pain is important.

There were some limitations to our research. First, this study used a cross-sectional design to analyze a sample of the general population. Therefore, a causal relationship could not be explored. However, this study aimed to observe the general population in Korea. Sampling error was minimized using a clustering multistage random sampling method. Second, the brief questionnaire used in this study to evaluate chronic knee pain did not describe its severity, source, or duration, probably by using a pain measurement tool with a scale (e.g. a numerical rating scale). Third, the relationship between sedentary behaviors and chronic knee pain determined here was dependent on ethnicity. The KNHANES is a nationwide survey targeting the general public in Korea. Therefore, as our findings are representative of the general Korean population, extrapolating our results to other populations may not be valid. Fourth, the confounders (age, BMI, smoking, alcohol consumption, occupation, education, household income, physical activity, depression, and sleep duration) used in this study did not significantly influence chronic knee pain; thus, they were used only as control variables. We did not identify the multicollinearity statistically because the confounders used in this study were considered to have little influence on chronic knee pain $[1,10,45]$. Future research must include statistical analysis of multicollinearity. Finally, the data obtained in this study from the KNHANES VI1 , VI-2, and VI-3 surveys were limited as the chronic knee pain survey was completed only by patients aged $>50$ years.

\section{Conclusions}

In conclusion, sedentary behaviors are significantly positively correlated with chronic knee pain. Obesity individuals with low physical activity and longer sedentary 
behaviors are more likely to suffer from chronic knee pain. However, among women participants who demonstrated high levels of physical activity, being sedentary for more than $10 \mathrm{~h}$ was more likely to cause chronic knee pain. Thus, the findings of our population-based study suggest that reductions in overall sedentary behaviors should be encouraged, particularly among individuals with chronic knee pain. High levels of physical activity are, particularly for women $>50$ years old and those with obesity.

\section{Supplementary information}

Supplementary information accompanies this paper at https://doi.org/10. 1186/s12889-019-7653-9.

Additional file 1: Table S1. Association between sedentary behaviors and chronic knee pain according to high physical activity using multivariable logistic regression by sex.

Additional file 2: Table S2. Association between sedentary behaviors and chronic knee pain according to BMI using multiple logistic regression by sex.

\section{Abbreviations}

BMI: Body mass index; Cls: Confidence intervals; KNHANES: Korea National Health and Nutrition Examination Survey; ORs: Odds ratios

\section{Acknowledgements}

We thank Mr. Park for providing the data necessary for our analysis.

\section{Authors' contributions}

SHL designed the concept of the study, analyzed the data and prepared the original manuscript draft. $\mathrm{HH}$ was responsible for the content of the manuscript, including data and analysis. CHS, SJY were responsible for revising the manuscript for important critical intellectual content. All authors have read and approved the final manuscript.

\section{Funding}

This study received no specific grant from any funding agency in the public, commercial, or not-for-profit sectors.

\section{Availability of data and materials}

Survey data are publicly available at (https://knhanes.cdc.go.kr/knhanes/main. do). All data from KNHANES VI are coded and freely available.

\section{Ethics approval and consent to participate}

The VI-1, VI-2, and VI-3 versions of the KNHANES were approved by the Institutional Review Board of the Korea Center for Disease Control and Prevention (approval no. 2013-07CON-03-4C, 2013-12EXP-03-5C, and 201501-02-6C). Each participant voluntarily participated and provided a written informed consent before participating in the study. Additionally, the i nstitutional review board (IRB) of the Jaseng Hospital of Korean Medicine waived approval because the KNHANES survey data are openly published. The informed consent was not required, as their information is fully anonymized and unidentified prior to analysis (JASENG 2018-12-001).

\section{Consent for publication}

Not applicable.

\section{Competing interests}

The authors declare that they have no competing interests.

\section{Author details}

'Jaseng Spine and Joint Research Institute, Jaseng Medical Foundation, Seoul, Republic of Korea. ${ }^{2}$ Department of Oriental Rehabilitation Medicine, National Rehabilitation Center, Seoul, Republic of Korea. ${ }^{3}$ Department of
Meridian and Acupoint, College of Oriental Medicine, Sang Ji University, Wonju, Republic of Korea.

Received: 22 April 2019 Accepted: 20 September 2019

Published online: 26 October 2019

\section{References}

1. Tuhina N. The epidemiology and impact of pain in osteoarthritis. Osteoarthr Cartil. 2013:21:1145-53.

2. Altman R, Alarcón G, Appelrouth D, Bloch D, Borenstein D, Brandt K, et al. The American College of Rheumatology criteria for the classification and reporting of osteoarthritis of the knee. Arthritis Rheum. 1986;29:1039-49.

3. Christopher WB, Christopher EJ, Jennifer GC. Knee pain in adults and adolescents: the initial evaluation. Am Fam Physician. 2018;98:576-85.

4. Nguyen US, Zhang Y, Zhu Y, Niu J, Zhang B, Felson DT. Increasing prevalence of knee pain and symptomatic knee osteoarthritis: survey and cohort data. Ann Intern Med. 2011;155:725-32.

5. Woo GJ, Oh GW. Prevalence of osteoarthritis among adults over 50 years old in Korea, 2010-2013. Public Health Wkly Rep, KCDC. 2015;8:82-4.

6. Hunter DJ, Schofield D, Callander E. The individual and socioeconomic impact of osteoarthritis. Nat Rev Rheumatol. 2014;10:437-41.

7. Woolf AD, Pfleger B. Burden of major musculoskeletal conditions. Bull World Health Organ. 2003;81:646-56.

8. Ettinger WH, Davis MA, Neuhaus JM, Mallon KP. Long term physical functioning in patients with knee osteoarthritis from NHANES I: effects of comorbid medical conditions. J Clin Epidemiol. 1994:47:809-15.

9. Realo A, Johannson J, Schmidt M. Subjective well-being and self-reported health in osteoarthritis patients before and after arthroplasty. J Happ Studies. 2016;18:1191-206.

10. Choi EY, Kim MJ. Factors associated with knee pain with different grades of knee osteoarthritis among Korean adults aged 50 years or more. Korean J Health Promot. 2016;16:145-52.

11. Deliens T, Deforche B, De Bourdeaudhuij I, Clarys P. Determinants of physical activity and sedentary behaviour in university students: a qualitative study using focus group discussions. BMC Public Health. 2015;15:201.

12. U.S. Department of Health and Human Services. Physical activity guidelines for Americans. 2nd ed; 2018. Available at: https://health.gov/paguidelines/secondedition/pdf/ Physical_Activity_Guidelines_2nd_edition.pdf. Accessed 1 July 2019

13. WHO. Global Recommendations on Physical Activity for Health. 2010. http:// whqlibdoc.who.int/ publications/2010/9789241599979_eng.pdf. (Accessed on 14 Jan 2019).

14. Ussery EN, Fulton JE, Galuska DA, Katzmarzyk PT, Carlson SA. Joint prevalence of sitting time and leisure-time physical activity among US adults, 2015-2016. JAMA. 2018:320:2036-8.

15. Harvey JA, Chastin SFM, Skelton DA. Prevalence of sedentary behavior in older adults: a systematic review. Int J Environ Res Public Health. 2013;10: 6645-61.

16. Healy GN, Wijndaele K, Dunstan DW, Shaw JE, Salmon J, Zimmet PZ, et al. Objectively measured sedentary time, physical activity, and metabolic risk: the Australian diabetes, obesity and lifestyle study (AusDiab). Diabetes Care. 2008;31:369-71.

17. Pate RR, O'Neill JR, Lobelo F. The evolving definition of "sedentary". Exerc Sport Sci Rev. 2008;36:173-8.

18. Chau JY, Grunseit AC, Chey T, Stamatakis E, Brown WJ, Matthews CE, et al. Daily sitting time and all-cause mortality: a meta-analysis. PLoS One. 2013:8:e80000.

19. Park SM, Kim HJ, Jeong HS, Kim HM, Chang BS, Lee CK, et al. Longer sitting time and low physical activity are closely associated with chronic low back pain in population over 50 years of age: a cross sectional study using the sixth Korea National Health and nutrition examination survey. Spine J. 2018; 18:2051-8.

20. Matthews CE, Chen KY, Freedson PS, Buchowski MS, Beech BM, Pate RR, et al. Amount of time spent in sedentary behaviors in the United States, 2003-2004. Am J Epidemiol. 2008;167:875-81.

21. Webber SC, Strachan SM, Pachu NS. Sedentary behavior, cadence, and physical activity outcomes after knee arthroplasty. Med Sci Sports Exerc. 2017:49:1057-65.

22. Caspersen CJ, Powell KE, Christenson GM. Physical activity, exercise, and physical fitness: definitions and distinctions for health-related research. Public Health Rep. 1985;100:126-31.

23. Lundebjerg $N$. Exercise prescription for older adults with osteoarthritis pain: consensus practice recommendations. J Am Geriatr Soc. 2001;49(6):808-23. 
24. Cho MH. Are Korean adults meeting the recommendation for physical activity during leisure time? J Phys Ther Sci. 2014;26:841-4.

25. Nelson ME, Rejeski WJ, Blair SN, Duncan PW, Judge JO, King AC, et al. Physical activity and public health in older adults: recommendations from the American College of Sports Medicine and the American Heart Association. Med Sci Sports Exerc. 2007;39:1435-45.

26. Garber CE, Blissmer B, Deschenes MR, Franklin BA, Lamonte MJ, Lee IM, et al. American College of Sports Medicine position stand. Quantity and quality of exercise for developing and maintaining cardiorespiratory, musculoskeletal, and neuromotor fitness in apparently healthy adults: guidance for prescribing exercise. Med Sci Sports Exerc. 2011;43:1334-59.

27. Wallis JA, Webster KE, Levinger $P$, Taylor NF. What proportion of people with hip and knee osteoarthritis meet physical activity guidelines? A systematic review and meta-analysis. Osteoarthr Cartil. 2013;21:1648-59.

28. Shim HY, Park M, Kim HJ, Kyung HS, Shin JY. Physical activity status by pain severity in patients with knee osteoarthritis: a nationwide study in Korea. BMC Musculoskelet Disord. 2018;19:380.

29. Holden MA, Nicholls EE, Young J, Hay EM, Foster NE. Exercise and physical activity in older adults with knee pain: a mixed methods study. Rheumatology. 2015;54:413-23.

30. Goulart AC, Rexrode KM. Health consequences of obesity in the elderly: a review. Curr Cardiovasc Risk Rep. 2007;1:340-7.

31. Reyes C, Leyland KM, Peat G, Cooper C, Arden NK, Prieto-Alhambra D. Association between overweight and obesity and risk of clinically diagnosed knee, hip, and hand osteoarthritis: a population-based cohort study. Arthritis Rheumatol. 2016:68:1869-75.

32. Pedisic Z, Grunseit A, Ding D, Chau JY, Banks E, Stamatakis E, et al. High sitting time or obesity: which came first? Bidirectional association in a longitudinal study of 31,787 Australian adults. Obesity. 2014;22:2126-30.

33. Van Uffelen JG, Watson MJ, Dobson AJ, Brown WJ. Sitting time is associated with weight, but not with weight gain in mid-aged Australian women. Obesity. 2010;18:1788-94.

34. Farrar JT, Young JP, LaMoreaux L, Werth JL, Poole RM. Clinical importance of changes in chronic pain intensity measured on an 11-point numerical pain rating scale. Pain. 2001:94:149-58.

35. Ku PW, Steptoe A, Liao Y, Hsueh MC, Chen LJ. A cut-off of daily sedentary time and all-cause mortality in adults: a meta-regression analysis involving more than 1 million participants. BMC Med. 2018;16:74.

36. Koster A, Caserotti P, Patel KV, Matthews CE, Berrigan D, Van Domelen DR, et al. Association of sedentary time with mortality independent of moderate to vigorous physical activity. PLoS One. 2012;7:e37696.

37. Hagströmer M, Oja P, Sjöström M. The international physical activity questionnaire (IPAQ): a study of concurrent and construct validity. Public Health Nutr. 2006:9:755-62.

38. World Health Organization. Regional Office for the Western Pacific. The AsiaPacific perspective: redefining obesity and its treatment. Sydney: Health Communications Australia; 2000. http://www.who.int/iris/handle/10665/206 936. Accessed 14 Jan 2019

39. Jhun HJ, Sung NJ, Kim SY. Knee pain and its severity in elderly Koreans: prevalence, risk factors and impact on quality of life. J Korean Med Sci. 2013; 28:1807-13.

40. Hassan A, Rahim M, Alireza N. Studying relation between sitting position and knee osteoarthritis. IOSR-JSPE. 2015;2:01-6.

41. Zobel I, Erfani T, Bennell KL, Makovey J, Metcalf B, Chen JS, et al. Relationship of buckling and knee injury to pain exacerbation in knee osteoarthritis: a webbased case-crossover study. Interact J Med Res. 2016;5:e17.

42. Felson DT, Niu J, McClennan C, Sack B, Aliabadi P, Hunter DJ, et al. Knee buckling: prevalence, risk factors, and associated limitations in function. Ann Intern Med. 2007:147:534-40

43. Defne K, Mahmut ND, Michael C. How can we strengthen the quadriceps femoris in patients with patellofemoral pain syndrome? Muscles Ligaments Tendons J. 2012;2:25-32

44. Susko AM, Fitzgerald GK. The pain-relieving qualities of exercise in knee osteoarthritis. Open Access Rheumatol. 2013;5:81-91.

45. Ron J, Kelvyn J, David M. Confounding and collinearity in regression analysis: a cautionary tale and an alternative procedure, illustrated by studies of British voting behavior. Qual Quant. 2018;52:1957-76.

\section{Publisher's Note}

Springer Nature remains neutral with regard to jurisdictional claims in published maps and institutional affiliations.

\section{Ready to submit your research? Choose BMC and benefit from:}

- fast, convenient online submission

- thorough peer review by experienced researchers in your field

- rapid publication on acceptance

- support for research data, including large and complex data types

- gold Open Access which fosters wider collaboration and increased citations

- maximum visibility for your research: over $100 \mathrm{M}$ website views per year

At $\mathrm{BMC}$, research is always in progress.

Learn more biomedcentral.com/submissions 